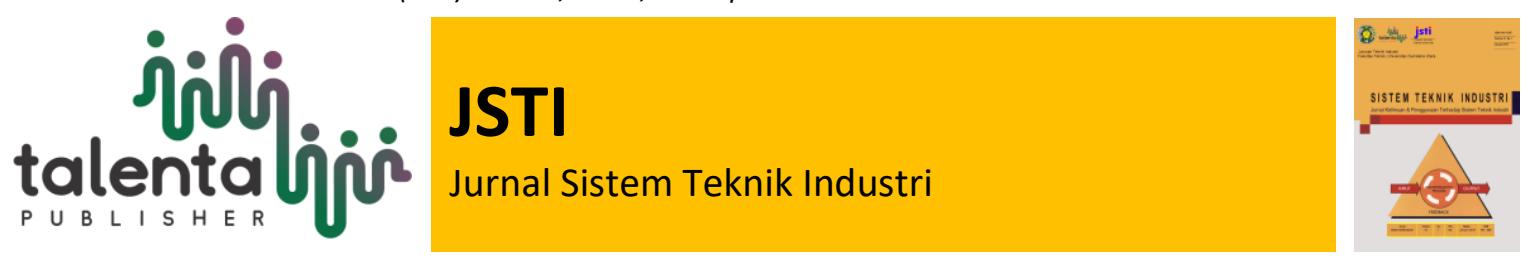

\title{
PENERAPAN FUZZY MIN-MAX MAMDANI UNTUK MEMPREDIKSI JUMLAH PRODUKSI DI PT.XYZ
}

\section{Ukurta Tarigan 1, Muhammad Faisal Ardiansyah1}

${ }^{1}$ Departemen Teknik Industri, Fakultas Teknik, Universitas Sumatera Utar, Medan,, Indonesia

\begin{abstract}
Abstrak. Kegiatan produksi merupakan salah satu kegiatan yang dilakukan dalam sebuah perusahaan khususnya PT XYZ yang bergerak dalam bidang manufaktur, produksi harus terus dilakukan agar dapat memenuhi permintaan. Menentukan jumlah yang akan diproduksi diperiode berikutnya sangat mempengaruhi keuntungan bersih perusahaan. Barang yang di produksi merupakan barang yang mudah rusak jika terlalu lama disimpan didalam gudang. Produksi yang terlalu banyak akan menimbulkan biaya simpan, jika produksi terlalu sedikit akan menimbulkan biaya stock out. Oleh sebab itu pengembangan dengan metode fuzzy dilakukan untuk memprediksi jumlah kebutuhan yang mendatang berdasarkan data masa lalu perusahaan. Diharapkan metode fuzzy mamdani yang akan diterapkan dapat mengoptimalkan jumlah produksi sehingga tidak timbul biaya-biaya lainya. Metode ini memungkinkan untuk mendapatkan jumlah produksi yang optimal karena data yang akan diprediksi berdasarkan data masa lalu perusahaan, data masa lalu yang digunakan ialah sebanyak 12 bulan, semakin banyak data masa lalu maka akan semakin akurat hasil prediksi dengan metode ini. Dengan begini maka keuntungan perusahaan akan meningkan karena tidak kehabisan barang serta tidak memiliki kelebihan barang yang disimpan digudang. Hasil dari metode fuzzy tsukamoto adalah sebanyak 107 untuk periode berikutnya. Kesimpulanya adalah pada periode berikutnya jumlah pesanan yang harus dilakukan adalah sebanyak 107 ,agar tidak terjadi kelebihan atau kekurangan stock
\end{abstract}

Kata Kunci: fuzzy mamdani, persediaan, cost inventory, stock out, perishable item

Abstract. Production activities are one of the activities carried out in a special company PT $X Y Z$ engaged in manufacturing, production must be carried out in order to meet demand. Determining the amount to be increased in the next period greatly benefits the company's net profit. The goods produced are items that can be easily damaged if stored for a long time in a warehouse. Toо much production will incur storage costs, if too little production will incur inventory costs. Therefore, the development of the fuzzy method is done to predict the number of future needs based on the company's past data. It is expected that the Mamdani fuzzy method to be applied can produce a number of production so that it does not incur other costs. This method allows to get the optimal amount of production because the data will be predicted based on the company's past data, the past data used is 12 months, the more past data the more accurate the results of predictions with this method. In this way the company profits will increase because there are no excess goods and also do not have excess goods purchased in the warehouse. The results of the tsukamoto fuzzy method are 107 for the next

*Corresponding author at: Jl. Almamater Padang Bulan, Medan Baru, Medan City, North Sumatra 20222 
period. The conclusion is that in the next period the number of orders that must be carried out is 107, so that there is no excess or lack of stock

Keywords: fuzzy mamdani, inventory, cost inventory, stock out, perishable item

Received 10 July 2019 | Revised 23 July 2019 | Accepted 23 July 2019

\section{Introduction}

Menentukan jumlah produksi barang perishable yang optimal dan waktu yang tepat merupakan sesuatu yang diinginkan semua perusahaan agar pendapatan perusahaan meningkan, begitu juga dengan PTXYZ dalam menentukan jumlah barang yang akan diproduksi berhubung barang yang diproduksi merupakan barang yang cepat rusak, sehingga tidak mudah dalam mengambil keputusan berapa yang akan di produksi. Banyaknya faktor yang terlibat juga menjadi salah satu sulitnya memprediksi jumlah barang yang akan diproduksi. Faktor - factor tersebut adalah permintaan maksimum, permintaan minimum, persediaan maksimum, persediaan minimum, produksi maksimum, produksi minimum, permintaan saat ini serta persediaan saat ini. Salah satu metode yang bisa digunakan dalam memprediksi dengan tepat adalah logika fuzzy .Logika fuzzy adalah metodologi sistem kontrol pemecahan masalah, yang cocok untuk diimplementasikan pada sistem, mulai dari sistem yang sederhana, sistem kecil, embedded system, jaringan PC, multichannel atau workstation berbasis akuisisi data, dan sistem kontrol, karena beberapat factor digunakan dalam perhitungan optimal jumlah yang akan diproduksi [1]. Logika fuzzy memiiki beberapa metode seperti metode mamdani, metode tsukamoto dan metode segeno. Setiap metode memiliki perhitungan dan algoritma yang berbeda dalam menentukan jumlah produksi optimal. Pada kasus ini, masalah yang timbul adalah bagaimana memprediksi jumlah barang yang diproduksi berdasarkan data permintaan dan data persediaan.

Penentuan jumlah produksi ini nantinya dapat kita cari dengan mengaplikasikan metode logika fuzzy. Logika fuzzy itu sendiri pertama kali diperkenalkan oleh Lotfi Zadeh yang merupakan perluasan dari logika konvensional Boolean yang telah diperluas untuk menangani konsep kebenaran parsial, yaitu nilai kebenaran yang terletak diantara kebenaran absolute (dipresentasikan dengan nilai 1) dan kesalahan absolute (dipresentasikan dengan nilai 0.5) Salah satu aplikasi logika fuzzy yang berkembang luas dewasa ini adalah dalam sistem inferensi kabur, yaitu sistem komputasi yang bekerja atas dasar penalaran kabur. Penalaran kabur (fuzzy reasoning), yang sering kali juga disebut penalaran hampiran (approximate reasoning).

Berdasarkan data permintaan yang diperoleh terlihat bahwa adanya ketidakpastian terhadap jumlah permintaan dari masyarakat. oleh karena itu, dalam tulisan ini penulis akan mengangkat tema tentang penerapan aplikasi logika fuzzy mamdani dalam perusahaan manufaktur. 


\section{METODE PENELITIAN.}

Pada tahap ini dikumpulkan informasi, keterangan dari narasumber melalui pihak perusahaan tentang produksi, teori-teori dari buku, rujukan dari artikel ataupun jurnal yang terkait dengan metode fuzzy Mamdani serta referensi lain yang dapat digunakan untuk menyelesaikan kasus ini. Wawancara dilakukan pada pihak perusahaan PT XYZ sebagai tempat pengambilan data. Hal yang mungkin harus diketahui adalah seberapa tinggi jumlah produk yang diproduksi dalam sebulan, faktor apa saja yang harus dipertimbangkan dalam memprediksi jumlah produk yang akan diproduksi tersebut.

Data yang diambil untuk digunakan dalam rancangan sistem ini adalah datadata per periode dari jumlah permintaan, persediaan, dan produksi produk selama rentang waktu dua tahun terakhir:

Table 1 Data Produksi

\begin{tabular}{cccc}
\hline Hari & Permintaan & Stock & Produksi \\
\hline 1 & 60 & 20 & 80 \\
2 & 90 & 30 & 100 \\
3 & 120 & 17 & 107 \\
4 & 120 & 27 & 130 \\
5 & 120 & 35 & 128 \\
6 & 120 & 33 & 122 \\
7 & 120 & 38 & 125 \\
8 & 97 & 19 & 78 \\
9 & 105 & 16 & 102 \\
10 & 105 & 16 & 105 \\
11 & 105 & 16 & 105 \\
12 & 90 & 19 & 93 \\
\hline
\end{tabular}

Dengan model prototyping, secara umum terdapat empat langkah untuk memprediksi jumlah produksi berdasarkan data persediaan dan jumlah permintaan dengan metode fuzzy Mamdani. Berikut algoritma untuk perhitungan sistematis logika fuzzy metode Mamdani dalam bentuk flowchart : 


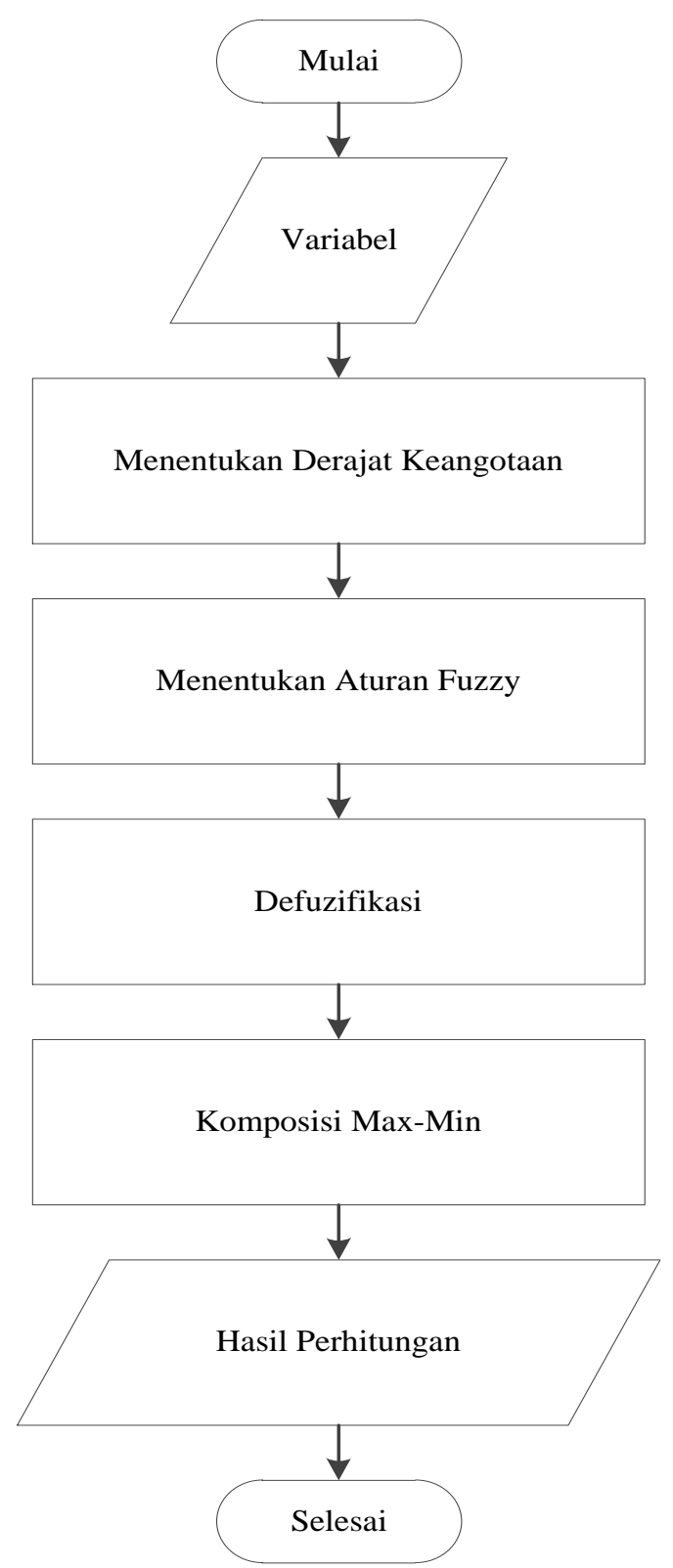

Figure 1 Flowchart Fuzzy Logic

\section{DATA DAN PEMBAHASAN}

Identifikasi data dilakukan dengan penentuan variabel yang diperlukan dalam melakukan perhitungan dan analisis masalah. Perusahaan dalam melakukan proses produksi dipengaruhi oleh beberapa faktor, diantaranya : jumlah permintaan, jumlah persediaan dan jumlah produksi. Terdapat beberapa langkah pada logika fuzzy mamdani dalam memprediksi jumlah barang yang diproduksi:

a. Menentukan Variabel Fuzzy dan Semesta Pembicaraan Pada penelitian ini, ada dua variabel yang digunakan yaitu variabel input dan variabel output. Variabel input terbagi atas jumlah persediaan dan jumlah permintaan, sedangkan variabel output 
adalah jumlah produksi. Semesta pembicaraan dari tiap variabel ditentukan berdasarkan data-data yang diperoleh dari hasil penelitian dan diurutkan berdasarkan dari nilai terkecilnya.

b. Pembentukan Himpunan Fuzzy

Pada metode Mamdani baik variabel input maupun variabel output dibagi menjadi satu atau lebih himpunan fuzzy. Semua variabel baik variabel input maupun output memiliki himpunan fuzzy yang sama yaitu, untuk jumlah permintaan memiliki himpunan fuzzy sedikit, sedang, dan banyak begitupula untuk jumlah persediaan dan jumlah produksi.

Table 2 Variabel dan Himpunan Data

\begin{tabular}{cc}
\hline Variabel & Himpunan \\
\hline & Sedikit \\
Permintaan & Sedang \\
& Banyak \\
& Turun \\
Produksi & Sedang \\
& Naik \\
& Berkurang \\
Persediaan & Tetap \\
& Bertambah \\
\hline
\end{tabular}

\section{c. Menentukan Fungsi Keanggotaan}

Fungsi keanggotaan ditentukan untuk mencari nilai derajat keanggotaan dari tiap himpunan fuzzy. Untuk himpunan fuzzy sedikit derajat keanggotaannya dicari dengan menggunakan fungsi keanggotaan kurva linear pertumbuhan dan untuk himpunan banyak menggunakan kurva linear penyusutan.

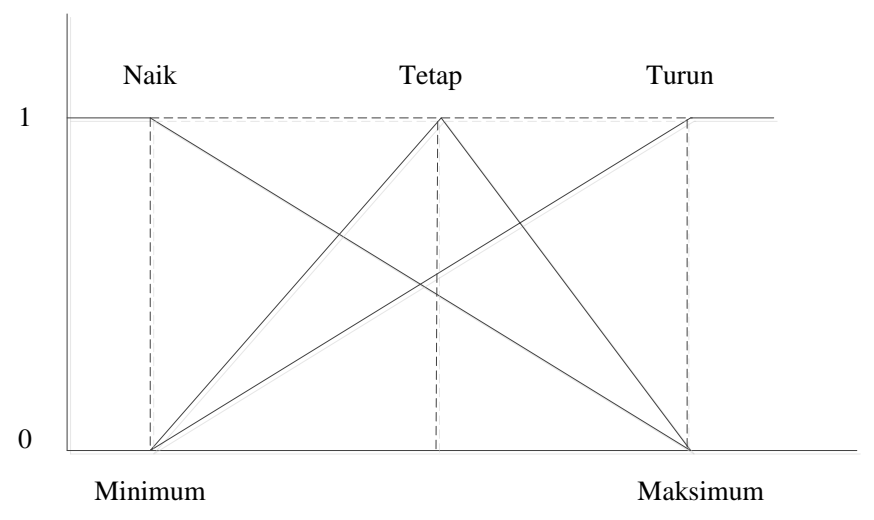

Figure 2 Kurva Linear

Gambar diatas menunjukan pola kurva linear minimum dan maksimum serta posisi naik, tetap dan turun. 


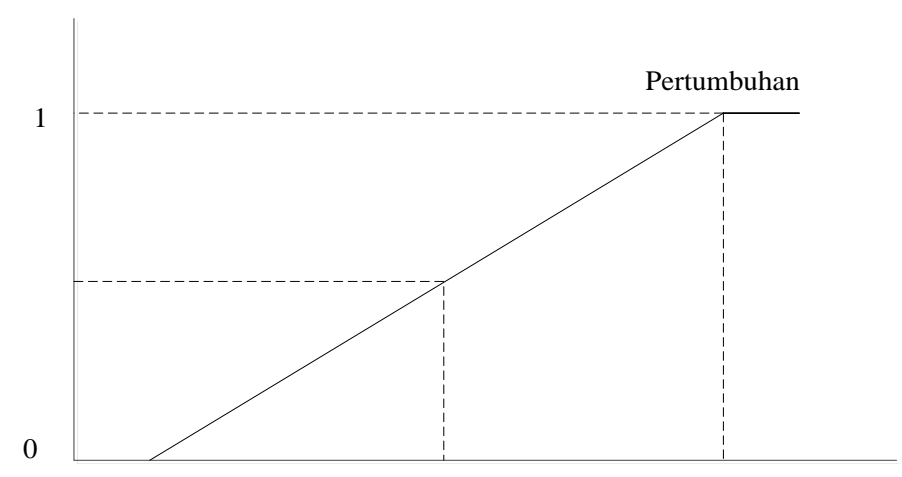

Figure 3 Kurva Linear Pertumbuhan

Gambar diatas menunjukan pola kurva linear minimum dan maksimum pertumuhan serta posisi naik, tetap dan turu

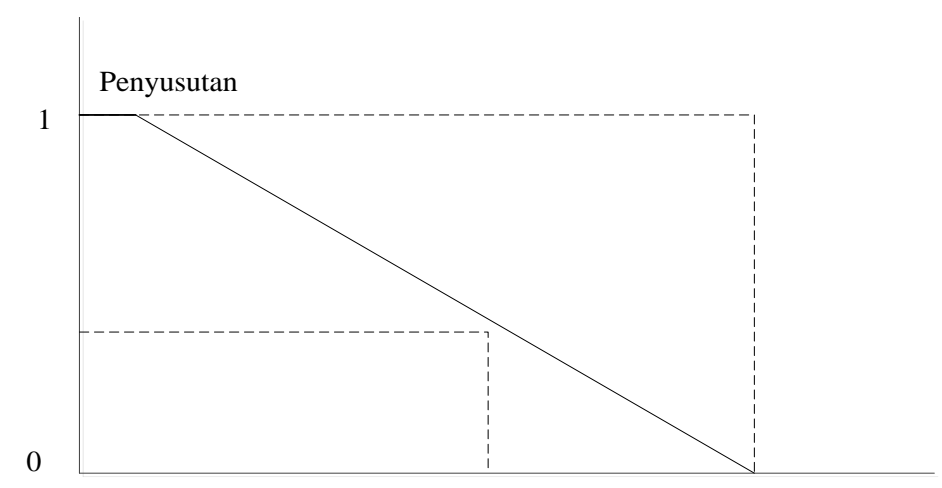

Figure 4 Kurva Linear Penyusutan

Gambar diatas menunjukan pola kurva linear minimum dan maksimum penyusutan serta posisi naik, tetap dan turun

Setelah dilakukan perhitungan metode fuzzy maka hasilnya dapat dilihat pada table dibawah:

Table 3 Variabel dan Logika Fuzzy

\begin{tabular}{cccc}
\hline & 1 & $\mathrm{x} \leq 60$ & 1 \\
Permintaan Turun & $\frac{120-x}{60}$ & $60 \leq x \leq 120$ & 0.333 \\
0 & $\mathrm{x} \geq 120$ & 0 \\
1 & $\mathrm{x}=90$ & 1 \\
Permintaan Sedang & $\frac{x-60}{30}$ & $60 \leq x \leq 90$ & 1.333 \\
& $\frac{120-x}{30}$ & $90 \leq x \leq 120$ & 0.666 \\
Permintaan Naik & 0 & $60 \leq x \mathrm{v} \mathrm{x} \geq 120$ & 0 \\
\hline
\end{tabular}




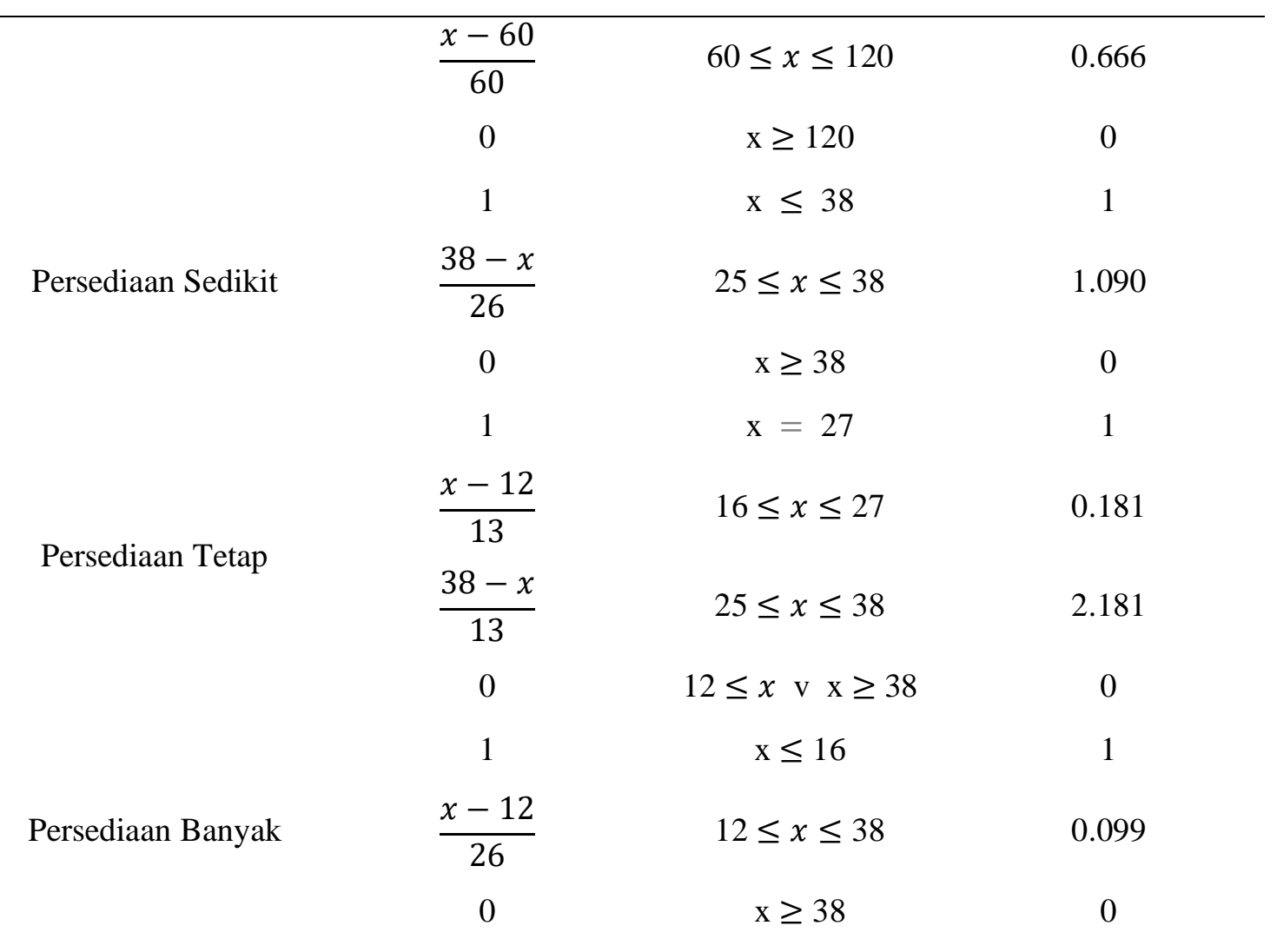

\section{d. Aturan Logika Fuzzy}

Pada metode Mamdani, fungsi implikasi yang digunakan untuk tiap-tiapaturan adalah fungsi min. Sebelum menentukan banyaknya jumlah produksinya harus ditentukan terlebih dahulu nilai -predikat, seperti di bawah ini:

[R1] IF jumlah permintaan sedikit AND persediaan sedikit THEN Produksi sedikit

$$
- \text { predikat } 1=\mu \mathrm{STK} \text { sedikit } \cap \mu \mathrm{STK} \text { sedikit }=\min (\mu \mathrm{LP} \text { sedikit } x, \mu \mathrm{STK} \text { sedikit }[y])
$$

Lihat himpunan produksi barang sedikit $=\mathrm{z} 1$

[R2] IF jumlah permintaan sedang AND persediaan sedang THEN Produksi sedang

$$
\text { -predikat2 }=\mu \mathrm{LP} \text { sedang } \cap \mu \mathrm{STK} \text { sedang }
$$

Aturan fuzzy dibuat sebanyak kebutuhan pneliti, pada kasus ini digunakan 9 aturan fuzzy seperti table dibawah: 
Table 4 Aturan Fuzzy

Keterangan:

\begin{tabular}{cccc}
\hline No & If & And & Then \\
\hline R1 & LP Turun & STK Banyak & PR Berkurang \\
R2 & LP Turun & STK Sedang & PR Berkurang \\
R3 & LP Turun & STK Sedikit & PR Berkurang \\
R4 & LP Tetap & STK Banyak & PR Berkurang \\
R5 & LP Tetap & STK Sedang & PR Tetap \\
R6 & LP Tetap & STK Sedikit & PR Bertambah \\
R7 & LP Naik & STK Banyak & PR Bertambah \\
R8 & LP Naik & STK Sedang & PR Bertambah \\
R9 & LP Naik & STK Sedikit & PR Bertambah \\
\hline
\end{tabular}

LP : Laju Pakai

STK : Stock

PR : Produksi

Dari seembilan kemungkinan unutk mencari nilai Z maka hasilya dapat dlihat pada table dibawah:

Table 5 Hasil Logika Fuzzy

\begin{tabular}{cccccccc}
\hline No & If & And & Then & Alpha & Nilai $\alpha$ & Nilai z & $\alpha^{*} \mathrm{z}$ \\
\hline R1 & LP Turun & STK Banyak & PR Berkurang & $\alpha 1$ & -0.09091 & 134.7273 & -12.2479 \\
R2 & LP Turun & STK Sedang & PR Berkurang & $\alpha 2$ & -0.18182 & 139.4545 & -25.3554 \\
R3 & LP Turun & STK Sedikit & PR Berkurang & $\alpha 3$ & 0.333333 & 112.6667 & 37.55556 \\
R4 & LP Tetap & STK Banyak & PR Berkurang & $\alpha 4$ & -0.09091 & 134.7273 & -12.2479 \\
R5 & LP Tetap & STK Sedang & PR Tetap & $\alpha 5$ & -0.18182 & 104 & -18.9091 \\
R6 & LP Tetap & STK Sedikit & PR Bertambah & $\alpha 6$ & 0.666667 & 112.6667 & 75.11111 \\
R7 & LP Naik & STK Banyak & PR Bertambah & $\alpha 7$ & -0.09091 & 73.27273 & -6.66116 \\
R8 & LP Naik & STK Sedang & PR Bertambah & $\alpha 8$ & -0.18182 & 68.54545 & -12.4628 \\
R9 & LP Naik & STK Sedikit & PR Bertambah & $\alpha 9$ & 0.666667 & 112.6667 & 75.11111 \\
\hline
\end{tabular}

Keterangan:

LP $\quad=$ Jumlah Produksi

STK = Persediaan

PR = Permintaan 
e. Penegasan atau Defuzzifikasi

Selanjutnya jumlah produksi dapat dicari dengan menggunakan penegasan (defuzzifikasi) dengan metode Centroid, yaitu sebagai berikut:

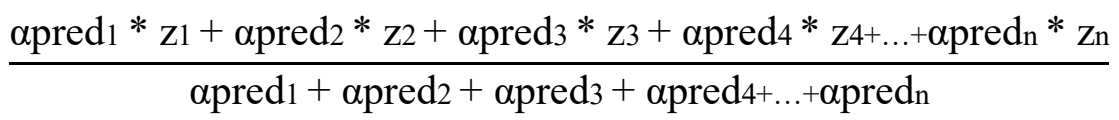

$$
\begin{aligned}
& \frac{0.090 * 134.72+\ldots+0.666 * 112.66}{0.090+\ldots+0.666} \\
& z=\frac{99.89}{0.84}=117.73
\end{aligned}
$$

Jumlah pesanan yang harus dilakukan adalah sebanyak 118, sehiingga tidak terjadi kekurangan atau kelebihan stock

\section{KESIMPULAN DAN SARAN}

1. Jumlah yang harus diproduksi pada hari ke-13 adalah sebnyak 118 , dengan jumlah seperti ini maka perusahaan bisa menghemat biaya simpan dan biaya kehabisan stock.

2. Logika fuzzy digunakan pada masalah yang berada pada posisi ketidak jelasan atau kabur seperti jumlah permintaan dan persediaan.

3. Perusahaan harus melakukan perhitungan scara rutin untuk mendapatkan hasil yang lebih optimal.

\section{REFERENSI}

[1] Kusumadewi, Sri 2003, Artificial Intelligence (Teknik dan Aplikasinya), Graha Ilmu, Yograkarta.

[2] Aplikasi Logika Fuzzy untuk Pendukung Keputusan. Yogyakarta: Graha Ilmu, 2004

[3] Dwi Martha .Penerapan Metode Fuzzy Mamdani Untuk Memprediksi Jumlah ProduksiMinyak Sawit Berdasarkan Data Persediaan Dan Jumlah Permintaan,

[4] Aplikasi Metode Fuzzy Min-Max (Mamdani) Dalam Menentukan Jumlah Produksi Perusahaan.

[5] Sofwan, A. Penerapan Fuzzy Logic Sistem Pengaturan Jumlah Air Berdasarkan Suhu dan Kelembaban. Yogyakarta, 2005.

[6] Susilo, Frans. Himpunan \& Logika Kabur serta Aplikasinya. Yogyakarta: Graha Ilmu, 2006. 